Published in final edited form as:

Curr Eye Res. 2005 July ; 30(7): 505-515.

\title{
A Review of Antimicrobial Peptides and Their Therapeutic Potential as Anti-Infective Drugs
}

\author{
Y. Jerold Gordon and Eric G. Romanowski \\ The Charles T. Campbell Ophthalmic Microbiology Laboratory, UPMC Eye Center, Department of \\ Ophthalmology, University of Pittsburgh, Pittsburgh, Pennsylvania, USA
}

\author{
Alison M. McDermott \\ University of Houston, College of Optometry, Houston, Texas, USA
}

\begin{abstract}
Purpose. Antimicrobial peptides (AMPs) are an essential part of innate immunity that evolved in most living organisms over 2.6 billion years to combat microbial challenge. These small cationic peptides are multifunctional as effectors of innate immunity on skin and mucosal surfaces and have demonstrated direct antimicrobial activity against various bacteria, viruses, fungi, and parasites. This review summarizes their progress to date as commercial antimicrobial drugs for topical and systemic indications.
\end{abstract}

Methods. Literature review.

Results. Despite numerous clinical trials, no modified AMP has obtained Food \& Drug Administration approval yet for any topical or systemic medical indications.

Conclusions. While AMPs are recognized as essential components of natural host innate immunity against microbial challenge, their usefulness as a new class of antimicrobial drugs still remains to be proven.

\section{Keywords}

antibiotics; antimicrobial peptides; cathelicidin; cationic peptides; defensins

\section{INNATE IMMUNITY AND ANTIMICROBIAL PEPTIDES (AMPS)}

Before the evolution of adaptive immunity in higher vertebrates added complexity, specificity, and memory to fight microbial challenge, a simpler, non-specific ancient system of innate immunity evolved 2.6 billion years ago and continues to function as the principal defense for almost all living organisms. ${ }^{1}$ Innate immunity is necessarily rapid, cidal, redundant, and multifunctional. ${ }^{2-4}$ The antimicrobial function of innate immunity is mediated, in part, by small cationic peptides with potent antimicrobial activity against Gram-positive and Gramnegative bacteria, fungi, parasites, and some viruses. ${ }^{5-7}$ The principal mechanism of rapid killing of microbial pathogens is attributed to perturbation of the microbial cell membrane, ${ }^{8}$, 9 but our understanding is incomplete and other mechanisms may also be operative. ${ }^{10-14}$ Human antimicrobial peptides (AMPs) such as defensins and cathelicidin (LL-37) are present in leukocytes and are also secreted by various epithelia in skin and mucosal surfaces including the ocular surface ${ }^{2,15-20}$ In addition to their antimicrobial role, AMPs also serve as important effector molecules in inflammation, immune activation, and wound healing. ${ }^{21-24}$

Correspondence: Y. Jerold Gordon, M.D., University of Pittsburgh, Department of Ophthalmology, Eye \& Ear Institute, Room 1023, 203 Lothrop St., Pittsburgh, PA 15213, USA. Fax: 412 647-5880; E-mail: gordonjs@ upmc.edu. 


\section{DRUG DEVELOPMENT OF ANTIMICROBIAL PEPTIDES}

The driving force for the development of newer anti-infectives is almost always the inevitable emergence of bacterial resistance to antibiotics following widespread clinical, veterinary, and animal agriculture (growth promoter in chickens, pigs, and feedlot cattle) usage. ${ }^{25,26}$ The pharmaceutical industry has continuously met this need by modifying existing antibiotics and developing newer antibiotics in a timely fashion. These successful efforts have produced the wide variety of currently available drug classes of antibiotics [beta lactams (penicillins, carbapenems, cepahalosporins), glycopeptides, macrolides, ketolides, aminoglycosides, fluoroquinolones, oxazolidinones, and others]. Similarly, there have been dramatic successes in developing effective antivirals to kill important clinical viral pathogens (e.g., HIV, herpesviruses, and influenza). However, the rapid emergence of resistance is even a greater problem for life-threatening viral infections. The best example remains HIV, where the rapid emergence of resistance to single drugs posed daunting clinical problems. The only effective solution to this problem was to develop combination therapy involving several antivirals with different mechanisms of inhibitory action. Currently, there are 19 different approved drugs for anti-HIV therapy in use as components of combination therapy. They include (1) nucleoside reverse transcriptase inhibitors, (2) nucleotide reverse transcriptase inhibitors, (3) nonnucleoside reverse transcriptase inhibitors, (4) proteases, and (5) viral entry blockers inhibitors. 27

Despite the success to date in antimicrobial development, the inexorable, ongoing emergence of resistance worldwide continues to spur the search for novel anti-infectives to replace and/ or supplement conventional antibiotics. Human defensins, cathelicidin, and a significant number of diverse AMPs from bacteria, viruses, plants, vertebrates, and invertebrates all appear to have a universal multidimensional signature (i.e., a common three-dimensional structure) that defines antimicrobial activity. ${ }^{28}$ Manipulation of this chemical structure to create designer synthetic peptides represents a promising strategy for the development of AMPs as a new class of drugs to prevent and treat systemic and topical infections.

For antimicrobial peptides, there are several different potential strategies for their general therapeutic application: (1) as single anti-infective agents, (2) in combination with conventional antibiotics or antivirals to promote any additive or synergistic effects, (3) as immunostimulatory agents that enhance natural innate immunity, and (4) as endotoxinneutralizing agents to prevent the potentially fatal complications associated with bacterial virulence factors that cause septic shock.

To date, the use of AMPs as single therapeutic antibiotic agents has received the most attention. However, the use of endotoxin-neutralizing agents as adjuncts to conventional antibiotic therapy has also been explored. As broad spectrum antimicrobials, AMPs may also have a role in treating important viral infections. ${ }^{14,29-31}$ Table 1 summarizes the theoretical advantages and disadvantages of developing antimicrobial peptides as single therapeutic antimicrobial agents. $21,32,33$ Despite many attractive attributes, the challenges of bringing a successful AMP to market remain formidable. There have been no published reports of commercial success in developing AMPs as topical ophthalmic agents (or any kind of therapeutic agent), and we will explore in this review the unique challenges and issues that the eye presents as a site of action for these novel anti-infective agents.

\section{HISTORY AND CURRENT STATUS OF CLINICAL DEVELOPMENT}

Of the potential pool of thousands of natural peptides and millions of synthetic peptide possibilities, relatively few have actually proceeded into clinical trials based on promising data from in vitro and animal studies. Despite a continuing optimism, ${ }^{34}$ a critical review of the 
literature to date suggests that commercial success remains elusive. In 2004, a list of antimicrobial peptides in clinical trials was published, ${ }^{34}$ and to date, none of the peptides described has obtained FDA approval for their various clinical indications. A more detailed review of some of these peptides is instructive of the challenges and difficulties encountered in the development of a new class of therapeutic drugs (Table 2).

\section{TOPICAL SKIN AND LOCAL APPLICATIONS (NONOCULAR)}

\section{Pexiganan (MSI-78)}

Pexiganan (MSI-78) (Magainin Pharmaceutical Inc, since renamed Genaera, Plymouth Meeting, PA, USA) was the first antimicrobial peptide to undergo commercial development. In 1987, Zasloff discovered that a cationic peptide in the skin of the African clawed frog Xenopus laevis had broad-spectrum antibacterial activity based on a "pore-formation" mechanism. 6,35 He called it magainin. Pexiganan, a synthetic 22-amino-acid analogue of magainin 2, demonstrated excellent in vitro broad-spectrum activity against 3109 bacterial clinical isolates. Resistant mutants could not be generated following repeated passage with subinhibitory concentrations. ${ }^{36}$ In two Phase III clinical trials involving 835 patients with infected diabetic foot ulcers, both topical pexiganan actetate $1 \%$ and oral ofloxacin $800 \mathrm{mg} /$ day achieved clinical cure or improvement in $90 \%$ of patients. Eradication of pathogens was achieved in $82 \%$ of the ofloxacin recipients compared to $66 \%$ of pexiganan recipients at the end of therapy. ${ }^{37}$ In 1999, FDA approval was denied because pexiganan was deemed to be no more effective that other antibiotics used to treat foot ulcers. ${ }^{38}$ Following this somewhat controversial decision, Genaera (www.genaera.com) discontinued its development.

\section{Iseganan (IB-367)}

Iseganan (IB-367) (Intrabiotics Pharmaceuticals, Inc, Mountainview, CA, USA; www.intrabiotics.com) is a synthetic protegrin 1 derived from the naturally occurring protegrins in pig leucocytes. ${ }^{39}$ As a cationic antimicrobial peptide, it has broad-spectrum in vitro antibacterial and antifungal inhibitory activity. A Phase IIa trial will explore the safety and efficacy of aerosolized iseganan $\mathrm{HCl}$ for decreasing the bacterial burden in the lungs and improving pulmonary function in cystic fibrosis patients with chronic respiratory infections. Iseganan was initially developed as a local mouthwash to prevent high-risk patients from developing ulcerative oral mucositis. In 502 patients receiving stomatotoxic chemotherapy in a Phase III clinical trial, treatment with oral iseganan mouthrinse $(9 \mathrm{mg} / \mathrm{dose})$ six times a day failed to prevent or reduce stomatitis, ulcerative oral mucositis, or its clinical sequelae relative to a placebo. ${ }^{40}$ In another Phase III clinical trial involving 545 patients receiving radiotherapy for head-and-neck malignancy, iseganan combined with standard-of-care oral hygiene (SOC) demonstrated no benefit in reducing the severity of ulcerative oral mucositis compared to placebo + SOC, and SOC alone. ${ }^{41}$ Based on these results, Intrabiotics abandoned development for this particular indication. ${ }^{42}$ More recently, the data monitoring committee of a Phase III clinical trial stopped the use of aerosolized iseganan for the prevention of ventilator-associated pneumonia because of a higher rate of pneumonia and mortality in the iseganan treatment group compared to the control group. (www.intrabiotics.com, Press Release June 23, 2004)

\section{Omiganan (MBI-226)}

Omiganen (MBI-226) (Microbiologix Biotech, Vancouver, BC, Canada) is a synthetic analogue of indolicidin, a cationic peptide originally purified from cytoplasmic granules of bovine neutrophils, that has broad antibacterial and antifungal activity in vitro. ${ }^{43}$ In a Phase III clinical trial involving more than 1400 patients in 29 U.S. centers, topical treatment with omiganan failed to demonstrate a statistically significant reduction in venous catheter-related bloodstream infections, the primary efficacy end-point, compared to povidone iodine as a control (www.drugs.com/nda_mbi-226.html, Press Release January 21, 2004). Nevertheless, 
in the same study, iseganan did achieve two statistically significant secondary efficacy endpoints: (1) a reduction in catheter colonization $(\mathrm{p}=0.002)$ and $(2)$ a reduction in catheterrelated local infections $(\mathrm{p}=0.004)$. In consultation with the FDA, the company is considering options of how to proceed.

MBI 594AN

MBI 594AN (Microbiologix Biotech, Vancouver, BC, Canada) is another cathelicidin- based, indolicidin-like novel, topical antibiotic under development for the treatment of acne. The most important bacterium associated with acne is Propionibacterium acnes ( $P$. acnes) for which antibiotic resistance has increased dramatically. The majority of isolates have a constitutive resistance to erythromycin, clindamycin, and to all other macrolide-lincosamide-streptogramin type B (MLS) antibacterials. ${ }^{44}$ Preclinical studies demonstrated excellent in vitro efficacy against sensitive and resistant $P$. acnes strains, and topical MBI 594AN was found to be nontoxic and nonirritating in animal models. A Phase IIb trial ( 255 patients at 9 centers) of topical 2.5\% MBI 594AN administered twice a day demonstrated a statistically significant reduction in inflammatory ( $\mathrm{p}<0.004)$, noninflammatory $(\mathrm{p}<0.037)$, and total lesions ( $\mathrm{p}<$ 0.001 ) at 6 weeks compared to a vehicle control. (www.mbiotix.com, Press Release November 17, 2003).

\section{Histatin Variants}

P113 (developed by Periodontix, Watertown, MA, USA, then acquired by Demegen, Pittsburgh, PA, USA; Pittsburgh Business Times July 16, 2001) is a 12-amino-acid cationic peptide based on histatins, naturally occurring antimicrobial peptides in the saliva. ${ }^{45} \mathrm{P} 113$ demonstrated excellent in vitro activity against Candida albicans and common Gram-positive and Gram-negative pathogens. The target indication for P113 is for treatment as a mouthrinse for oral candidiasis in HIV patients (Phase I/II clinical study completed), and P113D is to be used as an inhalation treatment for Pseudomonas aeruginosa lung infections in cystic fibrosis patients. Another peptide, D2A21, has shown promise as a topical antibiotic against Pseudomonas aeruginosa in rat models of skin infection 46 and burn wounds. ${ }^{47}$

XMP.629

XMP.629 [Xoma (US) LLC, Berkeley, CA, USA] is a 9-amino-acid peptide derived from bactericidal/permeability-increasing protein (BPI) that was created by reverse synthesis of the native 9mer peptide using $\mathrm{D}$ amino acids and substitution of two residues with napthyl-ala. XMP.629 has demonstrated potent antimicrobial activity against $P$. acnes with minimal bactericidal concentrations (MBC) ranging from 0.5 to $4.0 \mu \mathrm{g} / \mathrm{ml}$. A Phase I clinical trial established the safety of topical dermal therapy, but a Phase II clinical trial in 253 patients failed to demonstrate a benefit in the topical therapy of acne. (www.xoma.com, Press Release August 16, 2004).

\section{SYSTEMIC (PARENTERAL) APPLICATION}

\section{Neuprex (rBPI21)}

Neuprex $\left(\mathrm{rBPI}_{21}\right)$ [Xoma (US) LLC, Berkeley, CA, USA] bactericidal permeability-increasing protein (BPI) and $\mathrm{N}$-terminal fragments of $\mathrm{BPI}\left(\mathrm{rBPI}_{21}\right)$ bind and neutralize endotoxin and are potently bactericidal against Neisseria meningitidis. A Phase III clinical trial, carried out at 22 sites in the U.K. and the U.S.A., enrolled 393 children with severe meningococcemia. In addition to conventional antibiotic therapy, adjunctive parenteral therapy with $\mathrm{rBPI}_{21}(2 \mathrm{mg}$ / $\mathrm{kg}$ over $30 \mathrm{~min}$ followed by $2 \mathrm{mg} / \mathrm{kg}$ over $24 \mathrm{hr}$ ) failed to significantly reduce mortality [(7.4\% versus $9.9 \%$ (odds ratio 1.31 [95\% CI $0.62-2.74, \mathrm{p}=0.48$ ] compared to the placebo control $\left(0.2 \mathrm{mg} / \mathrm{ml}\right.$ human albumin solution) ${ }^{48}$ An open-label, single-center, dose-escalation, 
investigator-sponsored Phase I/II clinical trial of Nuprex $\left(\mathrm{rBPI}_{21}\right)$ to reduce inflammatory complications associated with pediatric open heart surgery patients is planned.

(www.xoma.com, Press Release October 2, 2003).

\section{ANTIMICROBIAL PEPTIDES IN PRECLINICAL DEVELOPMENT}

Several peptides have shown promise for possible drug development in preclinical studies. Helix Biomedix Inc, (Bothell, WA, USA) is developing a broad-spectrum microbicide to be used against bacteria (Garnerella, Prevatella, Peptostretococcus, and Bacteroids), fungi (Candida sp.), and viruses (HSV-2, HSV-1) that cause sexually transmitted diseases (STDs). 31 Plectasin, (Novozymes, Bagsvaerd, Denmark) is a recently discovered fungal defensin from Pseudoplectania nirgrella that is effective against Gram-positive bacteria in vitro and Streptococcus pneumoniae in mouse peritonitis and pneumonia models. ${ }^{49}$ Finally, Inimex Pharmaceuticals (Vancouver, BC, Canada) is developing immunoenhancement AMPs with no intrinsic antimicrobial inhibitory activity but that act by selectively upregulating innate immunity without overstimulation of proinflammatory mediators. Preliminary data demonstrated that combination therapy of these immunostimulating peptides with subtherapeutic doses of conventional antibiotics significantly lowered bacterial load in vivo in a murine $S$. aureus infection model. ${ }^{50}$ Additional studies are ongoing to explore this new approach to treat topical and systemic infections. ${ }^{51}$

\section{DEVELOPMENT OF AMPS FOR TOPICAL OPHTHALMIC USE}

\section{Issues and Challenges}

As previously stated, there are no ongoing trials at the present time to evaluate antimicrobial peptides for topical ocular infections. Furthermore, there are no published preclinical studies suggesting promising candidates. Because interest in commercial development of AMPs has been ongoing since the 1987 discovery of magainins, why has there been no apparent progress over the past 17 years in the ophthalmic field? Ophthalmic pharmaceutical companies have expressed intermittent interest in this potential new class of drugs and have supported contract research for exploratory in vitro and animal studies. However, a major disincentive has been the continuous pipeline of newer, highly successful, conventional antibiotics to replace older antibiotics with diminished efficacy due to increasing bacterial resistance. The recent introduction of topical gatifloxacin (Zymar, Allergan Inc., Irvine, CA, USA) and moxifloxacin (Vigamox, Alcon Laboratories Inc., Ft. Worth, TX, USA) for prophylaxis and treatment of ocular infections has again provided for another smooth transition away from the older drugs, ciprofloxacin (Ciloxan, Alcon Laboratories Inc.), and ofloxacin (Ocuflox, Allergan Inc.), to newer ones. ${ }^{52-54}$ Specifically, the emergence of increasing resistance among important ocular pathogens (e.g., Staphylococcus aureus, Pseudomonas aeruginosa) ${ }^{55-60}$ taken together with the expiration of patent protection on the older fluoroquinolones have led ophthalmic pharmaceutical companies to place marketing emphasis on the newer, more effective fluoroquinolones.

The potential advantages and disadvantages of antimicrobial peptides as single therapeutic agents for general use have already been summarized in Table 1. Although AMPs have many attractive qualities, the challenges for successful development for nonocular applications are considerable. The development of AMPs as topical agents for ophthalmic infections has several attractive features: (1) direct delivery to the infected site, (2) achievement of high local tissue levels through aggressive dosing, (3) possible combination therapy with conventional antibiotics $61-63$ to achieve a synergistic or additive antibacterial effect at nontoxic AMP concentrations. Furthermore, a broad-spectrum antimicrobial effective against both bacterial and viral ocular pathogens (HSV-1, adenoviruses ${ }^{14,29}$ ) may allow for better empirical treatment of superficial ocular infections by generalists. 
However, there are also potential drawbacks to putting AMPs in the eye. A candidate AMP that is non-toxic to skin (an epithelial surface protected by keratin) may turn out to be much more toxic to the epithelia of a delicate mucosal surface (e.g., conjunctiva) and the richly innervated, exquisitely sensitive corneal epithelium. The differences in context between the natural function of AMPs as part of innate immunity versus their repeated application in higher concentrations as topical ophthalmic drops or ointments raise a number of important theoretical issues regarding toxicity. As part of innate immunity, toxicity is controlled in vivo by several important mechanisms: (1) protected storage in granules (leucocyte defensins, cathelicidin), (2) epithelial synthesis as nontoxic, inactive propeptides requiring enzymatic activation for biological activity (cathelicidin), (3) minimal concentration because of the additive and synergistic effects achieved in combination with other effector molecules with overlapping antimicrobial functions, and (4) programmed, on site deactivating mechanisms to limit damage. 61 Topical AMPs as drugs can have their potential toxicity reduced by manipulating concentration, dose frequency, route of application, formulation, and possibly the concurrent administration of additional protective drugs. At worst, failure to successfully address the issues of ocular toxicity will inevitably lead to failure in clinical trials and denial of FDA approval. At best, limited but unavoidable toxicity can lead to poor patient compliance, reduced clinical efficacy and smaller profits if there are less toxic alternatives.

In addition to the major issue of ocular toxicity, the antimicrobial activity of AMPs may be reduced following interaction with tear film components. ${ }^{64,65}$ Furthermore, efficacy of AMPs on the ocular surface may be adversely affected by increased proteolysis, serum protein binding, ionic and $\mathrm{pH}$ changes, immune clearance from prior sensitization, and decrease residence time due to increased lacrimation, faster lacrimal drainage, and poor tissue penetration. The multieffector functions of AMPs may also prove confounding. 22,32 For example, AMPs can have either or both pro- and anti-inflammatory functions. ${ }^{21}$ If the antimicrobial efficacy of a specific peptide is also associated with proinflammatory effects, enhanced neutrophil recruitment may lead to a greater likelihood of corneal melting and perforation. If the antimicrobial efficacy of a specific peptide is also associated with enhanced cell migration and proliferation, fibroblasts may promote corneal scarring, and angiogenesis promoters may facilitate corneal neovascularization. The outcome of treating a corneal infection with an antimicrobial peptide could well be the successful killing of the invading pathogen, but the price paid may be a scarred, vascularized cornea. Not only will the patient have decreased vision if there is significant central scarring, but he will also have a poorer prognosis for successful vision restoration by corneal transplantation due to the presence of preexisting corneal vessels. Therefore, any peptide designed for topical ocular use must be carefully engineered to optimize its antimicrobial function and to reduce any other confounding biological functions.

Finally, before a pharmaceutical company will invest millions to develop a topical AMP ophthalmic product, the peptide must offer more than the promise of efficacy and safety in clinical trials as required for FDA approval. The AMP product must also be economical to manufacture by chemical or biological means, inexpensive to package, have an appropriate shelf life based on its chemical stability and formulation, and offer the likelihood of significant profits given the anticipated market and the available competing products. Taken together, these issues and challenges make it clear that the reason we do not yet have an ophthalmic antimicrobial peptide for the treatment of ocular infections is that these issues have not all been satisfactorily resolved for any peptide candidate, and the perceived need has not made it a program priority for any pharmaceutical company. 


\section{HISTORY OF IN VITRO AND ANIMAL STUDIES}

Next, we will review the sparse published literature and the experience of The Charles T. Campbell Laboratory and other leading investigators in the field to determine what progress has been made over the past 17 years toward the development of an AMP as a commercial ophthalmic anti-infective agent. The seminal work on the application of antimicrobial peptides to ophthalmology was begun in 1988 by Mark Mannis and colleagues at the University of California, Davis, and is summarized in his AOS thesis, which is highly recommended as an excellent introduction to the subject. ${ }^{61}$ Between 1989 and 2002, Mannis, Schwab, and others presented numerous studies at ARVO and published data on several different AMPs (rabbit defensin NP-1, various cecropins, and synthetic peptides created by computational drug design software) that they had tested in vitro and in an animal ocular model. Their focus was to determine the in vitro antimicrobial activity of various AMPs against pathogenic bacterial, fungal, and protozoal ocular isolates with the practical goals of developing effective preservatives for contact lens solutions and corneal storage media as well as a topical antimicrobial drug. Their research group reported that rabbit alpha defensin (NP-1) was effective against various bacterial ocular pathogens in phosphate buffer 66,67 and in modified corneal storage media ${ }^{68}$ and also stimulated epithelial cell growth ${ }^{69,70}$ Among the cecropin analogs tested, Shiva-11 was similarly active against a panel of ocular isolates 71 including gentamicin-resistant bacteria, ${ }^{72}$ showed potential as a preservative in timolol and contact lens solutions, and stimulated epithelial and fibroblast growth. ${ }^{73}$ Hecate, another cecropin analogue, inhibited various Acanthamoeba species in vitro. ${ }^{74}$ DeSousa reported that $\mathrm{D}_{5} \mathrm{C}$, another cecropin analogue, augmented contact lens disinfecting solutions against Pseudomonas aeruginosa 75 and was active against common Gram-positive and Gramnegative ocular pathogens and Candida in contact lens sterilization media and cornea storage media. ${ }^{75}$ In contrast, Schwab ${ }^{76}$ failed to demonstrate inhibitory activity for $\mathrm{D}_{5} \mathrm{C}$ or Nisin, a natural polypeptide derived from Streptococcus lactis, in modified corneal storage media (Optisol without antibiotics) at $4^{\circ} \mathrm{C}$ or $27^{\circ} \mathrm{C}$, although the addition of EDTA did augment the killing of Pseudomonas in vitro.

More recently, Mannis ${ }^{61}$ reported several synthetic peptides (CCI A, B, C and COL-1) that had been selected by "in virtuo" screening using a proprietary computer software program that optimized for activity against ocular bacterial pathogens (CyberChemics, Inc, Huntsville, AL, USA). As predicted, all of the synthetic peptides demonstrated significant inhibitory activity against a broad panel of bacterial and fungal ocular pathogens in a controlled system of $10 \mathrm{mM}$ sodium phosphate buffer. However in modified Optisol, only Staphylococcus epidermidis was inhibited at all temperatures by the peptides. Staphylococcus aureus was inhibited at $23^{\circ} \mathrm{C}$, but not at $4^{\circ} \mathrm{C}$, and Pseudomonas aeruginosa was not inhibited at all. The addition of EDTA augmented the killing of Pseudomonas but had no effect on Staphylococcus aureus. Finally, COL-1, which had been specifically designed to have anti-Pseudomonas activity, was tested in a robust rabbit keratitis model involving aggressive topical dosing for 4-6 days. Topical administration of COL-1 produced significant ocular toxicity in vivo and failed to demonstrate efficacy in the Pseudomonas rabbit keratitis model compared to an effective conventional antibiotic, tobramycin, using clinical signs and microbiological outcome measures. In the only other published study using topical AMPs in an ocular model, Nos-Barbera et al. ${ }^{77}$ reported in 1997 that a synthetic hybrid peptide from cecropin A and mellitin (bee venom) was equivalent to gentamicin in reducing clinical signs of infection in a Pseudomonas aeruginosa rabbit keratitis model. However, enthusiasm for this study is limited by the lack of any microbiological confirmation of antibacterial activity by the cecropin-mellitin hybrid in this model. 


\section{THE CAMPBELL LABORATORY EXPERIENCE (1996-2004)}

The Campbell Laboratory tested a variety of antimicrobial peptides over an 8-year period as part of contract research for several different companies. Binding confidentiality agreements preclude any detailed discussion of specific AMPs and the companies involved. Nevertheless, we believe that presentation of the results in general terms and insights gained still provide valuable information worth sharing in the ophthalmic literature.

The various antimicrobial peptides tested included synthetic analogues derived from various natural sources. These AMPs were tested for efficacy and toxicity in vitro and in rabbit ocular models of bacterial and viral infections (HSV-1, adenoviruses). Our general results can be summarized as follows: (1) Most AMPs, but not all, failed to demonstrate significant efficacy in animal models despite promising in vitro data. (2) Many AMPs demonstrated significant ocular toxicity following repeated topical administration. (3) Both efficacy (when present) and toxicity were dose-dependent and tended to occur at higher concentrations. (4) AMPs were generally disappointing as stand-alone therapy but could enhance the effectiveness of conventional antibiotics in some cases in vivo.

Richard O'Callaghan, Ph.D., Professor of Microbiology and Immunology, LSU Health Sciences Center, New Orleans, has tested numerous AMPs in vitro and some in ocular keratitis models. He confirms that his overall experience with AMPs was similar to our currently reported observations; namely, that AMPs usually demonstrated limited efficacy compared to conventional anti-infective therapies in ocular infection and were usually associated with significant ocular toxicity (personal communication). James M. Hill, Ph.D., Professor of Ophthalmology, Neuroscience, Pharmacology, \& Microbiology, LSU Eye Center, New Orleans, is another widely recognized authority on antimicrobial testing in animal ocular models. He reports, "My experience with most polypeptide antimicrobial agents is that they do not have sufficient efficacy compared to any currently accepted ophthalmic drugs, as measured in rabbit models of ocular infection. In general, these compounds have been safe and well tolerated when applied as topical drops to rabbit eyes. They do not inhibit corneal healing, nor do they reduce cell migration in animal models of wound healing" (personal communication).

In general, we found that a number of AMPs were effective invitro against Gram-positive and Gram-negative ocular pathogens under carefully controlled experimental conditions. This observation supports the previous findings of Mannis 61 who also observed reduced inhibitory activity of some AMPs under less stringent conditions (e.g., when corneal storage media replaced phosphate buffer; when the temperature was reduced from room temperature $\left(23^{\circ} \mathrm{C}\right)$ to a lower storage temperature $\left(4^{\circ} \mathrm{C}\right)$. In general, we also found that the more stringent the conditions required for optimized drug inhibition in vitro, the less the likelihood of success in vivo where inhibitory factors (binding proteins, lytic proteases, ionic changes, excess lacrimation, etc.) were expressed during acute inflammation on the infected ocular surface.

We believe that the issue of ocular toxicity is a major problem associated with the administration of topical AMPs as single therapeutic agents. We have observed repeatedly in our in vivo ocular models that AMPs are far more toxic in inflamed, infected eyes than in uninfected rabbit eyes. Therefore, the common practice of evaluating ocular toxicity of AMPs in a dose-escalation study in normal rabbit eyes is inadequate to accurately assess potential clinical toxicity of an anti-infective agent. Although it is true that toxicity demonstrated in normal animal eyes would likely predict a clinical toxicity issue, the absence of significant toxicity in normal eyes cannot provide the desired reassurance of clinical safety. Our observations and those of others show that normal eyes are not predictive of AMP toxicity in infected eyes. For example, Nos-Barbera et al. ${ }^{77}$ reported in 1997 that topical administration 
of cecropin-mellitin hybrids in a both high- and low-treatment regimens produced more signs of ocular toxicity than either PBS or gentamicin controls at $6 \mathrm{hr}$. Despite the obvious toxicity induced by the AMPs in infected PBS-treated control eyes, contralateral normal (uninfected) eyes showed no toxicity!

Another published example of this toxicity phenomenon was reported by Mannis in the Pseudomonas rabbit keratitis model. ${ }^{61}$ Similar to our data and that of Nos-Barbera, ${ }^{77}$ he found that the COL-1 peptide treated eyes were again more inflamed than the vehicle control eyes in the infection model at a peptide concentration $(50 \mu \mathrm{g} / \mathrm{ml})$ that was nontoxic in normal rabbit eyes. Critical review of his data also suggested that toxicity was a major issue based on (1) an enhanced perforation rate in the COL-1 group [8 of $17(47 \%)$ ] versus [2 of $9(23 \%)$ ] the vehicle control group, and (2) a reduced rate of surface sterilization in the COL-1 treated eyes 1 of 17 $(6 \%)$ versus 3 of $9(33 \%)$ for the vehicle control. This data is consistent with the interpretation that the toxic effects of the peptide may have interfered with the normal defense mechanisms responsible for wound healing and bacterial clearance on the ocular surface. Taken together, most animal studies indicate that the issue of ocular toxicity remains a major challenge for the successful development of AMPs as therapeutic ocular agents.

\section{PERSPECTIVES ON THE FUTURE OF A TOPICAL OPHTHALMIC AMP DRUG}

Of the thousands of potential synthetic peptides with antimicrobial activity, only a small fraction have been systematically studied and tested. The field is young, and it would be premature to conclude that AMPs have no apparent clinical role as therapeutic agents despite their evolutionary success as essential components of innate immunity in most species. The experience to date suggests that in vitro efficacy reproducibly demonstrated by many AMPs under controlled experimental conditions has not translated easily to success as single therapeutic agents in clinical trials when compared to conventional antibiotics. Furthermore, the unique challenges of toxicity for ophthalmic development will need to be overcome by custom peptide design, imaginative formulation, and strategies for reducing frequency of administration. The experience of The Campbell Laboratory with in vivo testing in animal models suggests that AMPs in combination with conventional antibiotics and/or antivirals (to promote any additive or synergistic effects) may prove to be a more successful developmental strategy for a topical ocular application. Finally, the therapeutic potential of AMPs lacking direct antimicrobial activity but having immunostimulatory properties that enhance natural innate immunity requires further assessment. Although some early preclinical studies were encouraging, much more data needs to obtained before the value of this intriguing proposition can be properly evaluated. In summary, although antimicrobial peptides are generally recognized as essential components of natural host innate immunity against microbial challenge, their promise as a new class of drugs and their value as external therapeutic agents still remain to be proven.

\section{Acknowledgements}

This work was supported by grant EY08227 (Y.J.G.), Core Grant for Vision Research EY08098, The Eye and Ear Foundation of Pittsburgh, Research for the Prevention of Blindness, and by University of Houston Gear grant EY-13175 (A.M.M.).

\section{References}

1. Kaufmann H, Medzhitov R, Gordon S, eds. The Innate Immune Response To Infection Washington, DC: ASM Press; 2004:465.

2. Ganz T. Defensins: antimicrobial peptides of innate immunity. Nat Rev Immunol 2003;3:710-720. [PubMed: 12949495]

3. Gallo RL, Nizet V. Endogenous production of antimicrobial peptides in innate immunity and human disease. Curr Allergy Asthma Rep 2003;3:402-409. [PubMed: 12906776] 
4. Beutler B. Innate immunity: an overview. Mol Immunol 2004;40:845-859. [PubMed: 14698223]

5. Hancock RE, Lehrer R. Cationic peptides: a new source of antibiotics. Trends Biotechnol 1998;16:8288. [PubMed: 9487736]

6. Zasloff M. Antimicrobial peptides of multicellular organisms. Nature 2002;415:389-395. [PubMed: 11807545]

7. Brogden KA, Ackermann M, McCray PB Jr, Tack BF. Antimicrobial peptides in animals and their role in host defences. Int J Antimicrob Agents 2003;22:465-478. [PubMed: 14602364]

8. van 't Hof W, Veerman EC, Helmerhorst EJ, Amerongen AV. Antimicrobial peptides: properties and applicability. Biol Chem 2001;382:597-619. [PubMed: 11405223]

9. Shai Y. Mode of action of membrane active antimicrobial peptides. Biopolymers 2002;66:236-248. [PubMed: 12491537]

10. Quinones-Mateu ME, Lederman MM, Feng Z, Chakraborty B, Weber J, Rangel HR, Marotta ML, Mirza M, Jiang B, Kiser P, et al. Human epithelial beta-defensins 2 and 3 inhibit HIV-1 replication. Aids 2003;17:F39-48. [PubMed: 14571200]

11. Sinha S, Cheshenko N, Lehrer RI, Herold BC. NP-1, a rabbit alpha-defensin, prevents the entry and intercellular spread of herpes simplex virus type 2. Antimicrob Agents Chemother 2003;47:494-500. [PubMed: 12543649]

12. Wang W, Owen SM, Rudolph DL, Cole AM, Hong T, Waring AJ, Lal RB, Lehrer RI. Activity of alpha- and theta-defensins against primary isolates of HIV-1. J Immunol 2004;173:515-520. [PubMed: 15210812]

13. Yasin B, Wang W, Pang M, Cheshenko N, Hong T, Waring AJ, Herold BC, Wagar EA, Lehrer RI. Theta defensins protect cells from infection by herpes simplex virus by inhibiting viral adhesion and entry. J Virol 2004;78:5147-5156. [PubMed: 15113897]

14. Gordon YJ, Huang LC, Romanowski EG, Yates KA, Proske RJ, McDermott AM. Human cathelicidin (LL-37), a multi-functional peptide, is expressed by ocular surface epithelia and has potent antibacterial and antiviral activity. Curr Eye Res 2005;30:385-394. [PubMed: 16020269]

15. Hattenbach LO, Gumbel H, Kippenberger S. Identification of beta-defensins in human conjunctiva. Antimicrob Agents Chemother 1998;42:3332. [PubMed: 10049242]

16. Haynes RJ, Tighe PJ, Dua HS. Antimicrobial defensin peptides of the human ocular surface. Br J Ophthalmol 1999;83:737-741. [PubMed: 10340986]

17. McNamara NA, Van R, Tuchin OS, Fleiszig SM. Ocular surface epithelia express mRNA for human beta defensin-2. Exp Eye Res 1999;69:483-490. [PubMed: 10548468]

18. McDermott AMRR, Pei Y, Huang L, Proske RJ. Defensin expression by the cornea: multiple signalling pathways mediate IL-1 beta stimulation of hbD-2 expression by human corneal epithelial cells. Invest Ophthalmol Vis Sci 2003;44:1859-1865. [PubMed: 12714616]

19. Narayanan S, Miller WL, McDermott AM. Expression of human beta-defensins in conjunctival epithelium: relevance to dry eye disease. Invest Ophthalmol Vis Sci 2003;44:3795-3801. [PubMed: 12939294]

20. Huang L, Proske RJ, McDermott AM. Expression of the peptide antibiotic LL-37/hCAP18 (Cathelicidin) by human corneal epithelial cells. Invest Ophthalmol Vis Sci 2003;44:ARVO E-abstr 1335 .

21. Koczulla AR, Bals R. Antimicrobial peptides: current status and therapeutic potential. Drugs 2003;63:389-406. [PubMed: 12558461]

22. Yang D, Biragyn A, Hoover DM, Lubkowski J, Oppenheim JJ. Multiple roles of antimicrobial defensins, cathelicidins, and eosinophil-derived neurotoxin in host defense. Annu Rev Immunol 2004;22:181-215. [PubMed: 15032578]

23. Yang D, Biragyn A, Kwak LW, Oppenheim JJ. Mammalian defensins in immunity: more than just microbicidal. Trends Immunol 2002;23:291-296. [PubMed: 12072367]

24. Huang L, Proske RJ, McDermott AM. Functional roles of the epithelial-derived antimicrobial-derived peptide LL-37 at the ocular surface. Invest Ophthalmol Vis Sci 2004;45:ARVO E-abstr 4940.

25. Verhoef J. Antibiotic resistance: the pandemic. Adv Exp Med Biol 2003;531:301-313. [PubMed: 12916802] 
26. Shea KM. Antibiotic resistance: what is the impact of agricultural uses of antibiotics on children's health? Pediatrics 2003;112:253-258. [PubMed: 12837918]

27. De Clercq E. Antiviral drugs in current clinical use. J Clin Virol 2004;30:115-133. [PubMed: 15125867]

28. Yount NY, Yeaman MR. Multidimensional signatures in antimicrobial peptides. Proc Natl Acad Sci USA 2004;101:7363-7368. [PubMed: 15118082]

29. Daher KA, Selsted ME, Lehrer RI. Direct inactivation of viruses by human granulocyte defensins. J Virol 1986;60:1068-1074. [PubMed: 3023659]

30. Zhang L, Yu W, He T, Yu J, Caffrey RE, Dalmasso EA, Fu S, Pham T, Mei J, Ho JJ, et al. Contribution of human alpha-defensin 1,2, and 3 to the anti-HIV-1 activity of CD8 antiviral factor. Science 2002;298:995-1000. [PubMed: 12351674]

31. Zhang L, Parente S, Harris SM, Falla TJ. Broad spectrum antimicrobial and antiviral peptides for prevention of sexually-transmitted diseases. American Society of Microbiology, New Orleans, LA, 2004, Abstract A-058.

32. Bradshaw J. Cationic antimicrobial peptides: issues for potential clinical use. BioDrugs 2003;17:233240. [PubMed: 12899640]

33. Yeaman MR, Yount NY. Mechanisms of antimicrobial peptide action and resistance. Pharmacol Rev 2003;55:27-55. [PubMed: 12615953]

34. Andres E, Dimarcq JL. Cationic antimicrobial peptides: update of clinical development. J Intern Med 2004;255:519-520. [PubMed: 15049887]

35. Zasloff M. Magainins, a class of antimicrobial peptides from Xenopus skin: isolation, characterization of two active forms, and partial cDNA sequence of a precursor. Proc Natl Acad Sci USA 1987;84:5449-5453. [PubMed: 3299384]

36. Ge Y, MacDonald DL, Holroyd KJ, Thornsberry C, Wexler H, Zasloff M. In vitro antibacterial properties of pexiganan, an analog of magainin. Antimicrob Agents Chemother 1999;43:782-788. [PubMed: 10103181]

37. Lamb HM, Wiseman LR. Pexiganan acetate. Drugs 1998;56:1047-1052. [PubMed: 9878992] discussion 1053-1044.

38. Moore A. The big and small of drug discovery. Biotech versus pharma: advantages and drawbacks in drug development. EMBO Rep 2003;4:114-117. [PubMed: 12612596]

39. Panyutich A, Shi J, Boutz PL, Zhao C, Ganz T. Porcine polymorphonuclear leukocytes generate extracellular microbicidal activity by elastase-mediated activation of secreted proprotegrins. Infect Immun 1997;65:978-985. [PubMed: 9038306]

40. Giles FJ, Rodriguez R, Weisdorf D, Wingard JR, Martin PJ, Fleming TR, Goldberg SL, Anaissie EJ, Bolwell BJ, Chao NJ, et al. A phase III, randomized, double-blind, placebo-controlled, study of iseganan for the reduction of stomatitis in patients receiving stomatotoxic chemotherapy. Leuk Res 2004;28:559-565. [PubMed: 15120931]

41. Trotti A, Garden A, Warde P, Symonds P, Langer C, Redman R, Pajak TF, Fleming TR, Henke M, Bourhis J, et al. A multinational, randomized phase III trial of iseganan $\mathrm{HCl}$ oral solution for reducing the severity of oral mucositis in patients receiving radiotherapy for head-and-neck malignancy. Int J Radiat Oncol Biol Phys 2004;58:674-681. [PubMed: 14967419]

42. Donnelly JP, Bellm LA, Epstein JB, Sonis ST, Symonds RP. Antimicrobial therapy to prevent or treat oral mucositis. Lancet Infect Dis 2003;3:405-412. [PubMed: 12837345]

43. Sader HS, Fedler KA, Rennie RP, Stevens S, Jones RN. Omiganan pentahydrochloride (MBI 226), a topical 12-amino-acid cationic peptide: spectrum of antimicrobial activity and measurements of bactericidal activity. Antimicrob Agents Chemother 2004;48:3112-3118. [PubMed: 15273128]

44. Tan HH. Topical antibacterial treatments for acne vulgaris: comparative review and guide to selection. Am J Clin Dermatol 2004;5:79-84. [PubMed: 15109272]

45. Kavanagh K, Dowd S. Histatins: antimicrobial peptides with therapeutic potential. J Pharm Pharmacol 2004;56:285-289. [PubMed: 15025852]

46. Chalekson CP, Neumeister MW, Jaynes J. Treatment of infected wounds with the antimicrobial peptide D2A21. J Trauma 2003;54:770-774. [PubMed: 12707542] 
47. Chalekson CP, Neumeister MW, Jaynes J. Improvement in burn wound infection and survival with antimicrobial peptide D2A21 (De-megel). Plast Reconstr Surg 2002;109:1338-1343. [PubMed: $11964988]$

48. Levin M, Quint PA, Goldstein B, Barton P, Bradley JS, Shemie SD, Yeh T, Kim SS, Cafaro DP, Scannon PJ, et al. Recombinant bactericidal/permeability-increasing protein (rBPI21) as adjunctive treatment for children with severe meningococcal sepsis: a randomised trial. rBPI21 Meningococcal Sepsis Study Group. Lancet 2000;356:961-967. [PubMed: 11041396]

49. Kristensen H. Plectasin—systematic applications of an antimicrobial peptide. American Society of Microbiology, New Orleans, LA, 2004, Abstract D-125.

50. Scott M, Dullaghan E, Lee K, Chung W, Lowden M, Calvert B, Finlay B, Hancock B. Peptides enhance the activity of antibiotics by boosting the innate immune response. American Society of Microbiology, New Orleans, LA, 2004, Abstract E-086.

51. Finlay BB, Hancock RE. Can innate immunity be enhanced to treat microbial infections? Nat Rev Microbiol 2004;2:497-504. [PubMed: 15152205]

52. Kowalski RP, Dhaliwal DK, Karenchak LM, Romanowski EG, Mah FS, Ritterband DC, Gordon YJ. Gatifloxacin and moxifloxacin: an in vitro susceptibility comparison to levofloxacin, ciprofloxacin, and ofloxacin using bacterial keratitis isolates. Am J Ophthalmol 2003;136:500-505. [PubMed: 12967804]

53. Kowalski RP, Romanowski EG, Mah FS, Yates KA, Gordon YJ. Topical prophylaxis with moxifloxacin prevents endophthalmitis in a rabbit model. Am J Ophthalmol 2004;138:33-37. [PubMed: 15234279]

54. Mather R, Karenchak LM, Romanowski EG, Kowalski RP. Fourth generation fluoroquinolones: new weapons in the arsenal of ophthalmic antibiotics. Am J Ophthalmol 2002;133:463-466. [PubMed: 11931779]

55. Goldstein MH, Kowalski RP, Gordon YJ. Emerging fluoroquinolone resistance in bacterial keratitis: a 5-year review. Ophthalmology 1999;106:1313-1318. [PubMed: 10406613]

56. Kowalski RP, Karenchak LM, Romanowski EG. Infectious disease: changing antibiotic susceptibility. Ophthalmol Clin North Am 2003;16:1-9. [PubMed: 12683244]

57. Rhee MK, Kowalski RP, Romanowski EG, Mah FS, Ritterband DC, Gordon YJ. A laboratory evaluation of antibiotic therapy for ciprofloxacin-resistant Pseudomonas aeruginosa. Am J Ophthalmol 2004;138:226-230. [PubMed: 15289131]

58. Garg P, Sharma S, Rao GN. Ciprofloxacin-resistant Pseudomonas keratitis. Ophthalmology 1999;106:1319-1323. [PubMed: 10406614]

59. Ball P. Emergent resistance to ciprofloxacin amongst Pseudomonas aeruginosa and Staphylococcus aureus: clinical significance and therapeutic approaches. J Antimicrob Chemother 1990;26(Suppl F): 165-179. [PubMed: 2127272]

60. Coronado VG, Edwards JR, Culver DH, Gaynes RP. Ciprofloxacin resistance among nosocomial Pseudomonas aeruginosa and Staphylococcus aureus in the United States. National Nosocomial Infections Surveillance (NNIS) System. Infect Control Hosp Epidemiol 1995;16:71-75. [PubMed: 7759821]

61. Mannis MJ. The use of antimicrobial peptides in ophthalmology: an experimental study in corneal preservation and the management of bacterial keratitis. Trans Am Ophthalmol Soc 2001;100:243271. [PubMed: 12545697]

62. Midorikawa K, Ouhara K, Komatsuzawa H, Kawai T, Yamada S, Fujiwara T, Yamazaki K, Sayama K, Taubman MA, Kurihara H, et al. Staphylococcus aureus susceptibility to innate antimicrobial peptides, beta-defensins and CAP18, expressed by human keratinocytes. Infect Immun 2003;71:3730-3739. [PubMed: 12819054]

63. Maisetta G, Batoni G, Esin S, et al. Activity of human beta-defensin 3 alone or combined with other antimicrobial agents against oral bacteria. Antimicrob Agents Chemother 2003;47:3349-3351. [PubMed: 14506056]

64. Rich D, Cullor J, Mannia MJ, et al. The in vitro activity of defensins against pseudomonas in the presence of human tears. Invest Ophthalmol Vis Sci 1990;31(suppl):Abstract:2203.

65. Huang L, Narayanan S, Redfern RL, McDermott AM. Human tears inhibit antimicrobial activity of human beta-defensin-2 in vitro. Invest Ophthalmol Vis Sci 2002;43:ARVO E-abstr 82. 
66. Cullor JS, Mannis MJ, Murphy CJ, Smith WL, Selsted ME, Reid TW. In vitro antimicrobial activity of defensins against ocular pathogens. Arch Ophthalmol 1990;108:861-864. [PubMed: 2112378]

67. Mannis M, Cullor J, Murphy CJ. The use of defensins for the eradication of ocular pathogens. Invest Ophthalmol Vis Sci 1989;30(Suppl):Abstract: 363.

68. Mannis M, Schwab IR, Dries D. Defensins as preservative in corneal storage medium. Invest Ophthalmol Vis Sci 1991;32(Suppl):Abstract: 1062.

69. Murphy CJ, Foster BA, Mannis MJ, Selsted ME, Reid TW. Defensins are mitogenic for epithelial cells and fibroblasts. J Cell Physiol 1993;155:408-413. [PubMed: 8482733]

70. Murphy C, Foster B, Mannis MJ. The stimulation of ocular cell growth by defensins of human and rabbit origins. Invest Ophthalmol Vis Sci 1989;30(Suppl):Abstract: 149.

71. Gunshefski L, Mannis MJ, Cullor JS, et al. In vitro antimicrobial activity of Shiva-11 against ocular pathogens. Cornea 1994;13:237-242. [PubMed: 8033574]

72. Gunshefski L, Macsai M, Granus V. Are synthetic cecropins (Shiva-11) effective against gentamicin resistant organism? Invest Ophthalmol Vis Sci 1993;34(Suppl):Abstract: 850.

73. Murphy C, Jaynes J, Iwahashi C. The modulation of ocular cell growth by cecropins. Invest Ophthalmol Vis Sci 1992;33(Suppl):Abstract: 828.

74. Gruzensky W, Mannis MJ, Schwab, IR. The use of a cecropin analog, Hecate, against Acanthamoeba in vitro. Invest Ophthalmol Vis Sci 1994;35(Suppl):Abstract: 1337.

75. de Sousa L, Mannis MJ, Schwab IR. The use of synthetic cepropin (D5C) in disinfecting contact lens solutions. CLAO J 1996;22:114-117. [PubMed: 8728617]

76. Schwab I, de Sousa LB, Mannis MJ. The use of defense peptides in corneal storage medica. Invest Ophthalmol Vis Sci 1995;36(Suppl):Abstract: 1017.

77. Nos-Barbera S, Portoles M, Morilla A, Ubach J, Andreu A, Paterson CA. Effect of hybrid peptides of cecropin A and mellitin in an experimental model of bacterial keratitis. Cornea 1997;16:101-106. [PubMed: 8985641] 
TABLE 1

Development of Antimicrobial Peptides as Anti-Infective Drugs ${ }^{a}$

Advantages

Broad-spectrum activity (antibacterial, antiviral, antifungal)

Rapid onset of killing

Cidal activity

Potentially low levels of induced resistance

Concomitant broad anti-inflammatory activities

Disadvantages

Discovery costs of synthesis and screening

Patent exclusivity for economic viability

Systemic and local toxicity

Reduced activity based on salt, serum, and $\mathrm{pH}$ sensitivity

Susceptibility to proteolysis

Pharmacokinetic (PK) and pharmacodynamic (PD) issues

Sensitization and allergy after repeated application

Natural resistance (e.g., Serratia marcescens)

Confounding biological functions (e.g., angiogenesis)

High manufacturing costs

${ }_{\text {Refs. } 21}, 32,33$. 


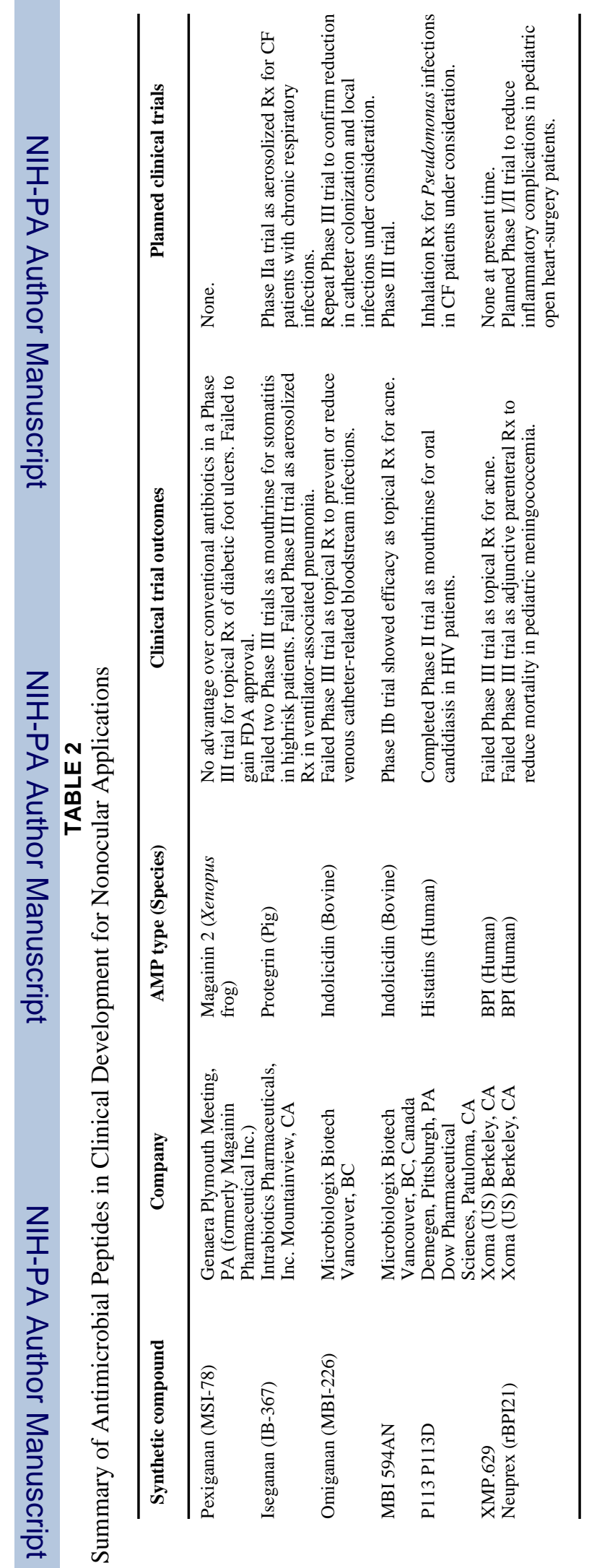

